Original Research Paper

\title{
Drop Weight Impact Behaviour of Tube Filled Polymeric Syntactic Foam
}

\author{
Yash M. Chordiya and Manmohan Dass Goel \\ Department of Applied Mechanics, Visvesvaraya National Institute of Technology, Nagpur, India
}

\section{Article history}

Received: 30-03-2019

Revised: 26-04-2019

Accepted: 23-05-2019

Corresponding Author:

Manmohan Dass Goel,

Visvesvaraya National Institute of Technology, Nagpur, India

Email: mdgoel@apm.vnit.ac.in

\begin{abstract}
Accidents are misfortune which could happen to anyone at any place at any time and it affects the vehicle as well as the occupants. Continuous research is being carried out for improving the crashworthiness of the vehicles with different materials. These materials plays important aspect in energy absorption and impact resistant design of the structure, wherein, presence of these materials highly affects the response of structures subjected to impact loading. In the present study, a non-linear finite element code LS-DYNA ${ }^{\circledR}$ is used for numerical simulation of drop weight impact hammer test. The material chosen for simulated testing is polymeric syntactic foam. In this study, effect of density of foam, foam material model, effect of drop height and effect of tube, filled with foam, on energy absorption of foam is studied. Herein, material model chosen for hammer is bilinear material model and crushable foam as well as piecewise linear plasticity model is used to model the foam. Behaviour of foam is compared in terms of reaction force, displacement time history and forcedisplacement variation. Energy absorption for each model is computed for different velocities considered in the present study and it is observed that tube plays an important role in enhancing the energy absorption of foam.
\end{abstract}

Keywords: Numerical Simulation, Impact, Drop Weight Impact Hammer Test, LS-DYNA ${ }^{\circledR}$, Polymeric Syntactic Foam, Foam Filled Tube

\section{Introduction}

There has been a tremendous increase in population of India and it ranks as second most populated country. Further, there is a great improvement in the living standard of the people which is evident from the report which states the number of cars used per thousand people (IPR, 2019; VPCR, 2015). This is due to the advancement in the transportation industry and due to vehicles, our life has become easier but there are always some drawbacks. It can be observed from road accidents in India statistics from year 2005-2016 that there has been tremendous increase in accidents (MRTHTRW, 2016). Accidents lead to loss of life and property and it can happen to anyone at any time. These events cannot be avoided completely but certain preventive measures can be taken. From the report on road safety in India, it has been reported that car owners are ready to pay more money for enhanced safety features in their vehicles (SaveLIFE Foundation, 2017). This is the reason that lot of research is being carried out in this field.

Crashworthiness of vehicles is a main factor to be considered for the design of the vehicles. For this purpose crash box, which are devices specially designed for impact testing, are filled with different materials and are allowed to impact. The response is recorded and a rough conclusion can be derived from the results when the actual impact occurs. It also gives a primary understanding about the behaviour of the material subjected to impact i.e., it basically gives an idea about crashworthiness of vehicle.

The materials which best suits the energy absorption profile are foams and the reason can be attributed to their internal structure. The foams have some voids present within it in the form of air or micro balloons which are specially induced during the formation of foam. Because of these voids, cellular rearrangement takes place which helps in the improved energy absorption when subjected to impact. Further, these foams find their application in safety guards, packaging, automobiles, blast lining materials and helmets. These foams are also used in under water application i.e., they are used for insulation of pipelines, construction of Remotely Or Human-Operated Vehicle (ROV or $\mathrm{HOV}$ ) and control surface of submarine (Barr and 
Bouamrata, 1988; Bowles, 1988; Rajendran et al., 2009; Gupta et al., 2013; Pinnoji et al., 2009).

Amongst the many test carried for impact testing drop weight impact hammer testing is the optimum choice because of its ease and flexibility. Many researchers worked on the impact test on different materials. The materials include foams, graphite-fiberreinforced composite, hybrid fiber engineered cementitious composite, concrete (Roesset et al., 1994; Banthia et al., 1989; Zhang et al., 2017; Sahu et al., 2019; Zhang et al., 2007). Researchers also tried different variations of drop weight impact test for obtaining material stress-strain curves. Johnson and Browne (2002) said that drop tower facilities provided a quick and inexpensive means of conducting dynamic tests and it has been used extensively by transportation industry. Behrooz et al. (2013) worked on dropped weight machine to calculate energy absorption of composite materials. Gunawan et al. (2011) developed a drop weight impact hammer machine so that the machine could be used for validating various numerical simulation models and the machine was equipped with various different sensors. Bhattacharya et al. (2006) performed normal impact test but used different type of triggering mechanism, it consisted of Infra-Red (IR) source and detector, when specimen was dropped it interrupted with line of IR beam and it activated the mechanism. Goyal and Buratynski (2000) introduced a new method of testing where the free dynamics of the object to be tested is considered. In this test the drop table hits the ground and just before impact the object is free to move naturally.

Foams in broader sense are good energy absorbers but the most commonly used are closed cell aluminium foam, polymeric foams and syntactic foams (Aymerich et al., 1997; Aldoshan et al., 2017; Goel et al., 2014; 2013; 2015; Matsagar, 2014; Chordiya and Goel, 2018). It is evident from the literature that numerical simulation of drop weight impact hammer test is scarce. Also, the study of numerical simulation of tube filled with polymeric syntactic foam has not been done before. Numerical simulation is good option because it requires less manpower and different variations can be tried by making some changes in the program.

Hence, present investigation focuses on numerical simulation of drop weight impact test of polymeric syntactic foam considering the effect of density, velocity, effect of tube which is filled with foam and effect of material model used for foam using LS-DYNA ${ }^{\circledR}$.

\section{Energy Absorption Mechanism}

The reason that foams are good energy absorbers is because of their internal structure. Figure 1 shows the Scanning Electron Micrograph (SEM) of glass hollow particle/vinyl ester syntactic foam (Gupta et al., 2013). It is evident from the structure that voids are present and because of these voids cellular rearrangement takes place when subjected to impact or blast and this results in the deformation of foam. It is evident by the principle of energy conservation that kinetic energy gets converted into fracture energy or deformation energy of foam which means that if deformation in foam is more, it leads to higher energy absorption.

The general stress-strain profile of foam is characterized into three regions i.e., elastic region, plateau region, densification region. In the stress-strain curve, important region for energy absorption is the plateau region because maximum energy absorption takes place under this region. It can be observed from Fig. 2 that under plateau region there is increase in strain without much increase in the stress i.e., increase in displacement without much increase in force which is the basis of energy absorption principle (Gupta et al., 2013).

\section{Effect of Tube}

The tubes are provided to increase impact resistance of the foam. The total energy absorbed is given by Equation 1:

$$
W_{v}^{\text {Filledtube }}=W_{v}^{\text {Tube }}+W_{v}^{\text {Foam }}+W_{v}^{\text {int }}
$$

where, $W$ is energy absorbed per unit volume (by the entities mentioned in superscript). $W_{v}^{\text {int }}$ is the energy absorbed by the interaction between the tube and foam (Ashby et al., 2009). The energy absorbed by the tube and foam is obtained by Equation 2 and 3 as:

$$
\begin{aligned}
& W_{v}^{\text {Tube }}=2^{1 / 3}\left(\frac{\rho}{\rho_{s}}\right)^{1 / 5} \sigma_{y s} \varepsilon_{D}^{\text {Tube }} \\
& W_{v}^{\text {Foam }}=0.3\left(\frac{\rho}{\rho_{s}}\right)^{1.5} \sigma_{y s} \varepsilon_{D}^{\text {From }}
\end{aligned}
$$

where, $\rho$ is density of foam, $\rho_{s}$ is the density of the parent material, $\sigma_{y s}$ is the yield stress and $\varepsilon_{D}$ is the densification strain it can be calculated by Equation 4 .

$$
\varepsilon_{D}\left(1-\alpha_{1} \frac{\rho}{\rho_{s}}\right)
$$

where, $\alpha_{1}$ ranges from 1.5 to 2 . From Equation 1 it can be observed that the total energy absorbed is an algebraic addition of $W_{v}^{\text {Tube }}, W_{v}{ }^{\text {Foam }}$ and $W_{v}^{\text {int }}$ Hence, considering effect of tube leads to improved energy absorption by the foam and same is investigated in the present study. 


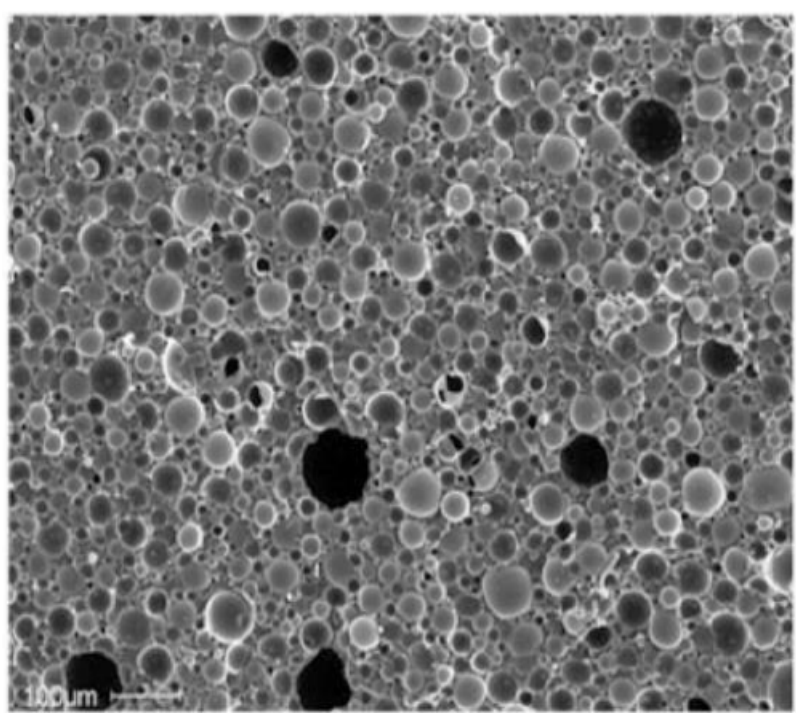

Fig. 1: Scanning Electron Micrograph (SEM) of glass hollow particle/vinyl ester syntactic foam (Gupta et al., 2013)

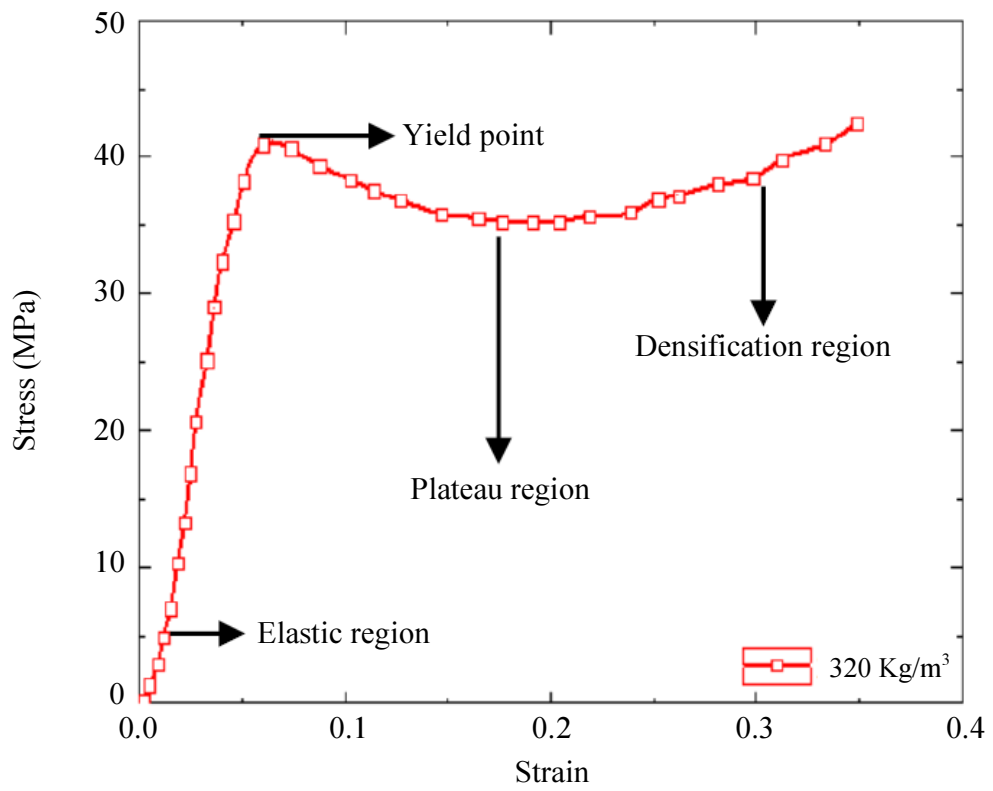

Fig. 2: Quasi static stress strain curve for Polymeric syntactic foam (Gupta et al., 2013)

\section{Validation of FE-Scheme}

Any new numerical simulation is said to be validated if it results in good agreement with experimental results or with another numerical simulation which is validated using experimental results. For improved confidence, present FE model is validated using experimental and numerical simulated results reported by Rajendran et al. (2009). The dimensions of the hammer and foam are taken as suggested by Rajendran et al. (2009). Herein, an impact hammer is modelled using eight noded hexahedral elements in LS-DYNA ${ }^{\circledR}$ with dimensions as $155 \mathrm{~mm}$ diameter and $720.2 \mathrm{~mm}$ length having weight of $106 \mathrm{~kg}$. MAT_003 (MAT_PLATIC_KINEMATIC) of
LS-DYNA ${ }^{\circledR}$ material library is used as material model for hammer (LS-DYNA, 2019). The properties of hammer are reported in Table 1.

The material chosen for testing is closed cell aluminium foam. It is tested under different drop velocities and energy absorption is computed for understanding the material behaviour under impact. Foam is modelled using eight noded hexahedral elements with dimensions as $80 \mathrm{~mm}$ diameter and 100 mm length. MAT_063 (MAT_CRUSHABLE_FOAM) of LS-DYNA ${ }^{\circledR}$ material library is used as material model for hammer (LS-DYNA, 2019). Finite element model of hammer impacting the foam is shown in Fig. 3. 
The automatic surface to surface contact interaction is used between bottom of hammer and top of foam. Clamped boundary condition is applied at the bottom of the foam. The material card for foam requires elastic modulus, density, tension cut-off, Poisson's ratio, damping co-efficient and a stress-strain curve (LSDYNA, 2019). The values are $160 \mathrm{MPa}, 570 \mathrm{~kg} / \mathrm{m}^{3}, 4$ $\mathrm{MPa}, 0,0.05$, respectively and stress-strain curve for foam is reported in Fig. 4.

Rajendran et al. (2009) With the help of mesh convergence study, mesh size chosen for hammer and foam is $20 \mathrm{~mm}$ and $10 \mathrm{~mm}$, respectively. This corresponds to 18400 elements for hammer and 1050 elements for the foam. The results reported by the author are for various drop velocities but for validation purpose a drop velocity of $5.42 \mathrm{~m} / \mathrm{s}$, which corresponds to $1.5 \mathrm{~m}$ drop height, is chosen.

Table 1: Material properties of the hammer

\begin{tabular}{ll}
\hline Properties & Values \\
\hline Modulus of Elasticity, $E(\mathrm{GPa})$ & 210 \\
Poisson's Ratio, $\mu$ & 0.30 \\
Yield Stress, $\sigma_{\mathrm{y}}(\mathrm{MPa})$ & 230 \\
Tangent Modulus, $E_{\mathrm{t}}(\mathrm{MPa})$ & 800 \\
Density, $\rho\left(\mathrm{kg} / \mathrm{m}^{3}\right)$ & 7800 \\
\hline
\end{tabular}

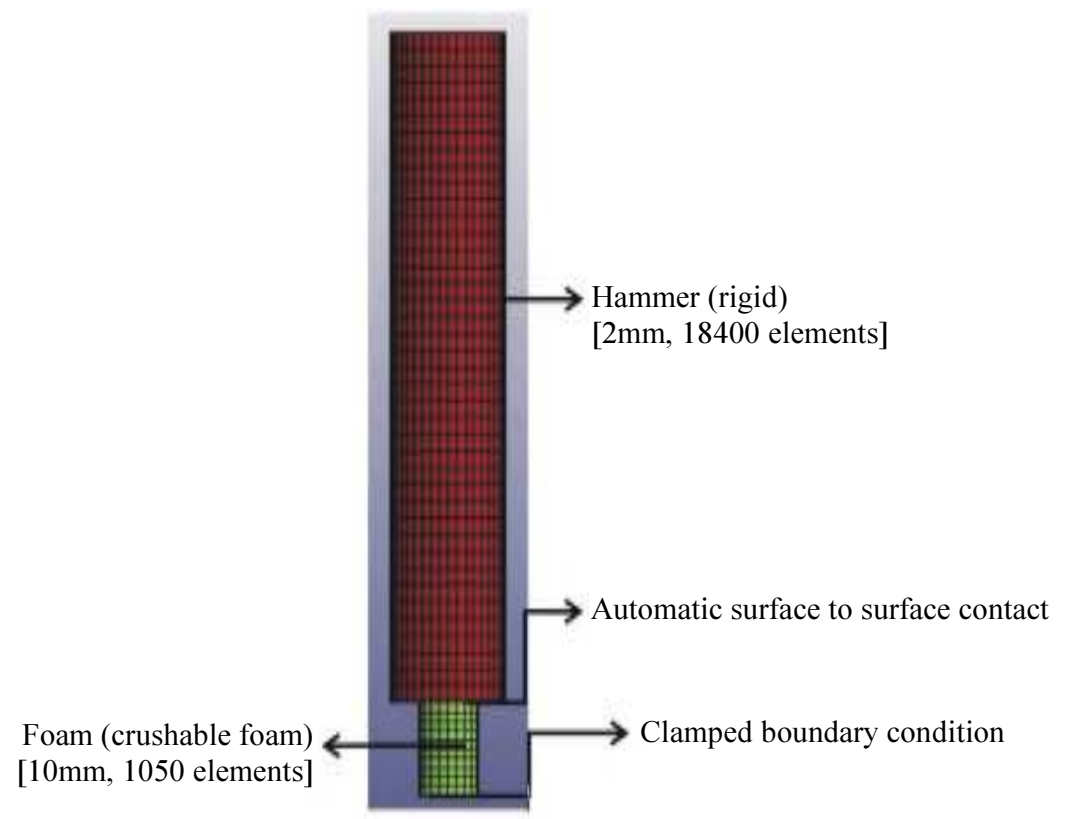

Fig. 3: FE model of aluminum foam and drop hammer in LS-DYNA ${ }^{\circledR}$

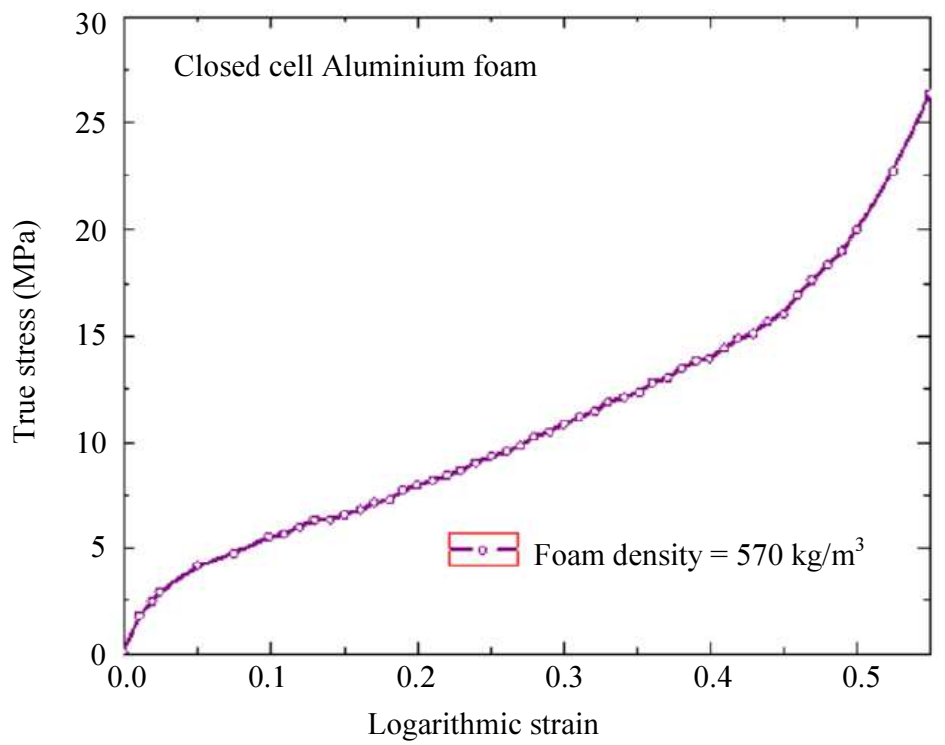

Fig. 4: True stress-strain curve for aluminum foam used for validation of FE scheme as per Rajendran et al. (2009) 
The total runtime for analysis is taken as $0.025 \mathrm{~s}$ and results are extracted at an interval of $0.0025 \mathrm{~s}$ as suggested by author (Rajendran et al., 2009). Figure 5 depicts comparison of displacement time history reported by Rajendran et al. (2009) and present numerical simulation. The locations of points whose data are to be extracted are same as suggested by the Rajendran et al. (2009). From the comparison, it is observed that results are in acceptable error range $(5 \%)$ so the current FE model is said to be validated.

\section{Working of Drop Weight Impact Hammer}

The working of drop weight impact hammer machine is very simple; the hammer is raised upto a certain height and is allowed to impact test specimen. Here potential energy of hammer gets converted into kinetic energy and then this kinetic energy gets converted into internal energy of the specimen. Hence the basic working principle of the impact hammer machine is conservation of energy principle. One important aspect which must be paid due attention during the design of an energy absorbing structure is the energy dissipation technique, it must be transferred in a controlled manner and at a predetermined rate. Further transferred energy should be strictly inelastic ( $\mathrm{Lu}$ and $\mathrm{Yu}, 2003$ ).

The actual working of the machine is very simple hammer is raised upto a certain predefined height and a perfect vertical impact over test specimen is ensured with help of guided columns, as the hammer strikes the specimen the sensors activates and suitable data is extracted, then using suitable data acquisition system crushing force, speed data is analyzed (Zhang et al., 2017; Bhattacharya et al., 2006; Aymerich et al., 1997). In the present simulation, free fall velocity is given to the simulated hammer model which corresponds to the drop height with an assumption that there is no friction between clamp-hoist mechanism, post and hammer in actual machine.

\section{Material Properties and Finite Element Modelling}

The material chosen for testing is polymeric syntactic foam. Complete structure of polymeric syntactic foam is divided in three substructures: reinforcement, matrix resin and hollow particle material. The syntactic foam chosen for this study has nanoclay, epoxy and glass as the three substructures, respectively. This foam contains $5 \%$ by volume of nanoclay and $60 \%$ by volume of glass particles. These foams also has same regions i.e., elastic region, plateau region and densification region. Figure 6 shows quasi static stressstrain curve for all the densities of foam considered in the present study (Gupta et al., 2013).

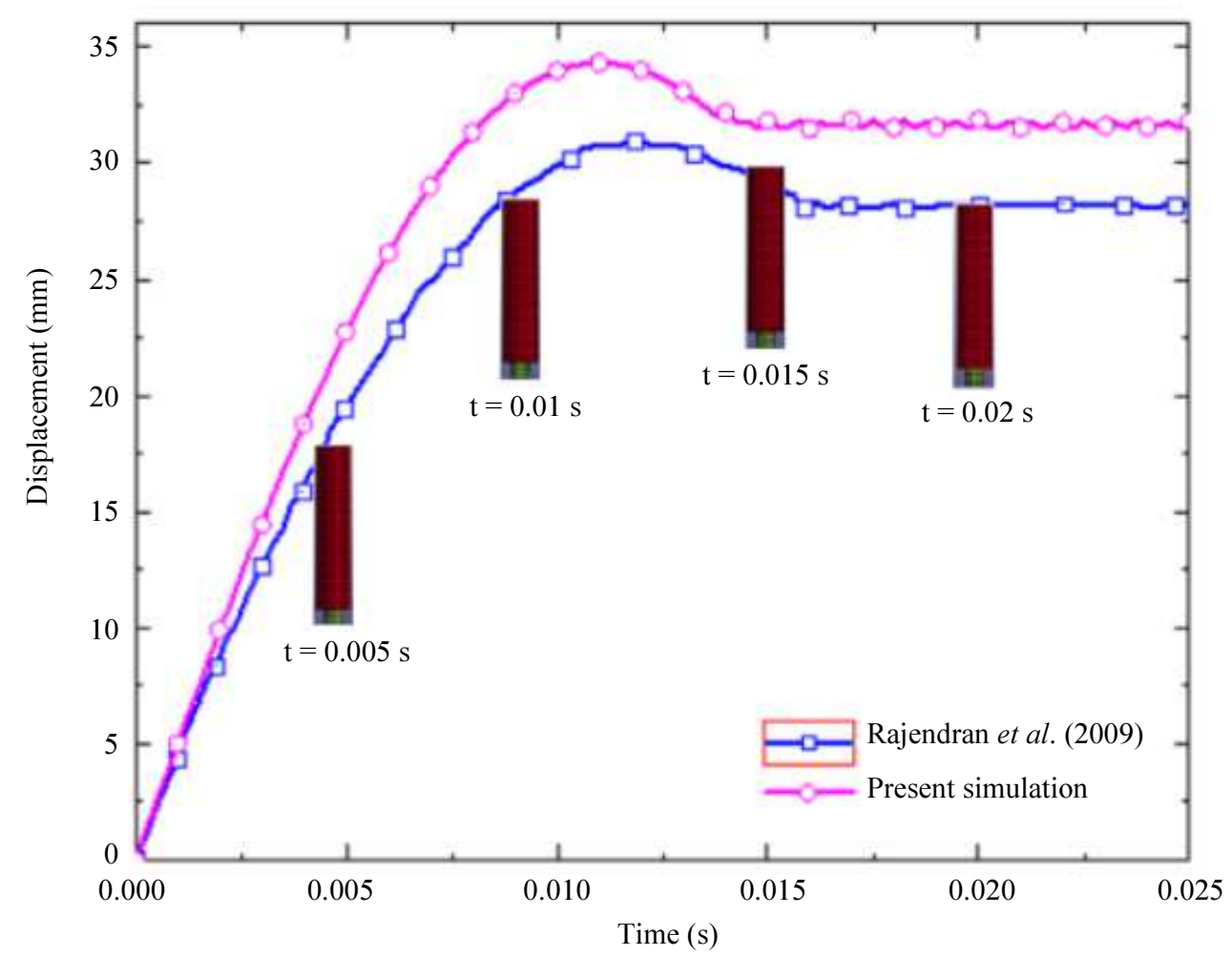

Fig. 5: Variation of displacement-time history at top of foam in comparison with the results reported by Rajendran et al. (2009) 
Table 2: Material properties for polymeric syntactic foam (Gupta et al., 2013)

\begin{tabular}{|c|c|c|c|}
\hline \multirow[b]{2}{*}{$\begin{array}{l}\text { Properties } \\
\text { Density, } \rho\left(\mathrm{kg} / \mathrm{m}^{3}\right)\end{array}$} & \multicolumn{3}{|c|}{ Values } \\
\hline & 220 & 320 & 460 \\
\hline Modulus of elasticity, $E(\mathrm{GPa})$ & 1.5 & 1.5 & 1.5 \\
\hline Tension cut off, $\sigma_{\mathrm{t}}(\mathrm{MPa})$ & 8.0 & 8.0 & 8.0 \\
\hline Poisson's ratio, $\mu$ & 0.3 & 0.3 & 0.3 \\
\hline Damping co-efficient, $\eta$ & 0.3 & 0.3 & 0.3 \\
\hline Yield stress, $\sigma_{y}$ & 30.0 & 40.0 & 60.0 \\
\hline Tangent modulus, $E_{t}(\mathrm{MPa})$ & 200.0 & 200.0 & 200.0 \\
\hline
\end{tabular}

In the present study, material model and properties chosen for hammer is same as chosen for the validation i.e., MAT 003 (MAT PLASTIC KINEMATIC) and for foam in addition to MĀT 063 (MAT CRUSHABLE FOAM), MAT 024 (MAT PIECEWISE LINEAR PLASTICITY) is used which is available in material library of LS DYNA ${ }^{\circledR}$. The material properties of foam are reported in Table 2 and stress-strain curves are given in Fig. 6.

In this study, effect of tube is also considered and it is modelled using MAT_003 (MAT_PLASTIC_KINEMATIC). The material card requires data such as density $(\rho)$, modulus of elasticity $(E)$, poisson ratio $(\mu)$, yield stress $\left(\sigma_{y}\right)$, tangent modulus $\left(E_{\mathrm{t}}\right)$ and their respective values are $2700 \mathrm{~kg} / \mathrm{m}^{3}, 70 \mathrm{GPa}, 0.3$, $364 \mathrm{MPa}$ and $700 \mathrm{MPa}$ (Pinnoji et al., 2009).

The simulation is carried out for three different drop velocities which corresponds to different strain rates as $30 / \mathrm{s}, 40 / \mathrm{s}, 60 / \mathrm{s}$ and the drop velocities are $3.13 \mathrm{~m} / \mathrm{s}, 4.42$ $\mathrm{m} / \mathrm{s}, 6.26 \mathrm{~m} / \mathrm{s}$ which corresponds to a drop height of 0.5 $\mathrm{m}, 1 \mathrm{~m}, 1.5 \mathrm{~m}$, respectively. The termination time of the analysis is set to be $0.025 \mathrm{~s}$ and the results are extracted at an interval of $0.00125 \mathrm{~s}$. This time interval is chosen because it satisfies the relation $\Delta_{\mathrm{t}} \leq l / C_{\mathrm{L}}, l$ is the length of smallest division of sample and $C_{\mathrm{L}}$ is speed of wave which travels through the material (Johnson, 1972). Clamped boundary condition is applied at bottom of hammer and automatic surface to surface contact is used between top of foam and bottom of hammer.

\section{Results and Discussion}

Numerical simulation is done for three densities, three velocities, two material models for foam and effect of tube is also considered. So, this totally adds up to thirty six models and to compare these models reaction force time history, displacement time history and energy absorption for all the models is studied. Figure 7 shows reaction force time history and it is evident that increase in density leads to increase in reaction force. Same trend is followed in case of increase in velocity which is true for both the material models considered i.e., crushable foam and piecewise linear plasticity model. The effect of tube in foam filled tube on reaction force time history for both the material models is considerable for densities $220 \mathrm{~kg} / \mathrm{m}^{3}$ and $320 \mathrm{~kg} / \mathrm{m}^{3}$ whereas for $460 \mathrm{~kg} / \mathrm{m}^{3}$ slight change is observed for velocity of $6.26 \mathrm{~m} / \mathrm{s}$.
From the comparison of peak reaction force responses of models comprising MAT 063 (MAT_CRUSHABLE FOAM) material model with foam fille $\overline{\text { d tube and foam }}$ only configurations, for all densities of foam considered in the present investigation under a common velocity of 6.26 $\mathrm{m} / \mathrm{s}$, it is observed that foam filled tube models result in $12.34 \%, \quad 12.76 \%, 9.08 \%$ higher reaction force in comparison with foam only models for density $220 \mathrm{~kg} / \mathrm{m}^{3}$, $320 \mathrm{~kg} / \mathrm{m}^{3}, 460 \mathrm{~kg} / \mathrm{m}^{3}$, respectively. Similar behaviour but different values are observed for other velocities considered in the present investigation.

Whereas, for

MAT 024 (MAT PIECEWISE LINEAR PLASTICITY)

comparison of peak reaction force responses of models comprising foam filled tube and foam only configurations, for all densities of foam considered in the present investigation under a common velocity of $6.26 \mathrm{~m} / \mathrm{s}$, it is observed that foam filled tube model results in $9.75 \%, 8.11 \%, 7 \%$ higher reaction force in comparison with foam only model for density 220 $\mathrm{kg} / \mathrm{m}^{3}, 320 \mathrm{~kg} / \mathrm{m}^{3}, 460 \mathrm{~kg} / \mathrm{m}^{3}$, respectively. Similar behaviour but different values are observed for other velocities considered in the present investigation.

Figure 8 depicts the displacement time history and it can be observed that increase in density leads to decrease of displacement for both the material models considered. Effect of tube on displacement time history is clearly observed for MAT 063 (MAT_CRUSHABLE_FOAM) material model for all the drop velocities considered whereas for MAT_ 024 (PIECEWISE LINEAR PLASTICITY) the difference can observed can be observed for velocities $4.42 \mathrm{~m} / \mathrm{s}$ and $6.26 \mathrm{~m} / \mathrm{s}$ and negligible difference is observed for $3.13 \mathrm{~m} / \mathrm{s}$.

From the comparison of peak displacement responses of models comprising MAT_ 063 (MAT_CRUSHABLE_FOAM) material model with foam filled tube and foam only configurations, for all densities of foam considered in the present investigation under a common velocity of $6.26 \mathrm{~m} / \mathrm{s}$, it is observed that foam filled tube model results in $12.09 \%, 10.42 \%$, $8.17 \%$ lower displacement in comparison with foam only model for density $220 \mathrm{~kg} / \mathrm{m}^{3}, 320 \mathrm{~kg} / \mathrm{m}^{3}, 460$ $\mathrm{kg} / \mathrm{m}^{3}$, respectively. Similar behaviour but different values are observed for other velocities considered in the present investigation.

Whereas, for MAT (MAT PIECEWISE LINEAR PLASTICITY)

comparison of peak displacement responses of models comprising foam filled tube and foam only configurations, for all densities of foam considered in the present investigation under a common velocity of 6.26 $\mathrm{m} / \mathrm{s}$, it is observed that foam filled tube model results in $10.66 \%, 9 \%, 6.62 \%$ lower displacement in comparison with foam only model for density $220 \mathrm{~kg} / \mathrm{m}^{3}, 320 \mathrm{~kg} / \mathrm{m}^{3}$, $460 \mathrm{~kg} / \mathrm{m}^{3}$, respectively. Similar behaviour but different values are observed for other velocities considered in the present investigation. 
Yash M. Chordiya and Manmohan Dass Goel / International Journal of Structural Glass and Advanced Materials Research 2019, Volume 3: 40.55 DOI: 10.3844/sgamrsp.2019.40.55

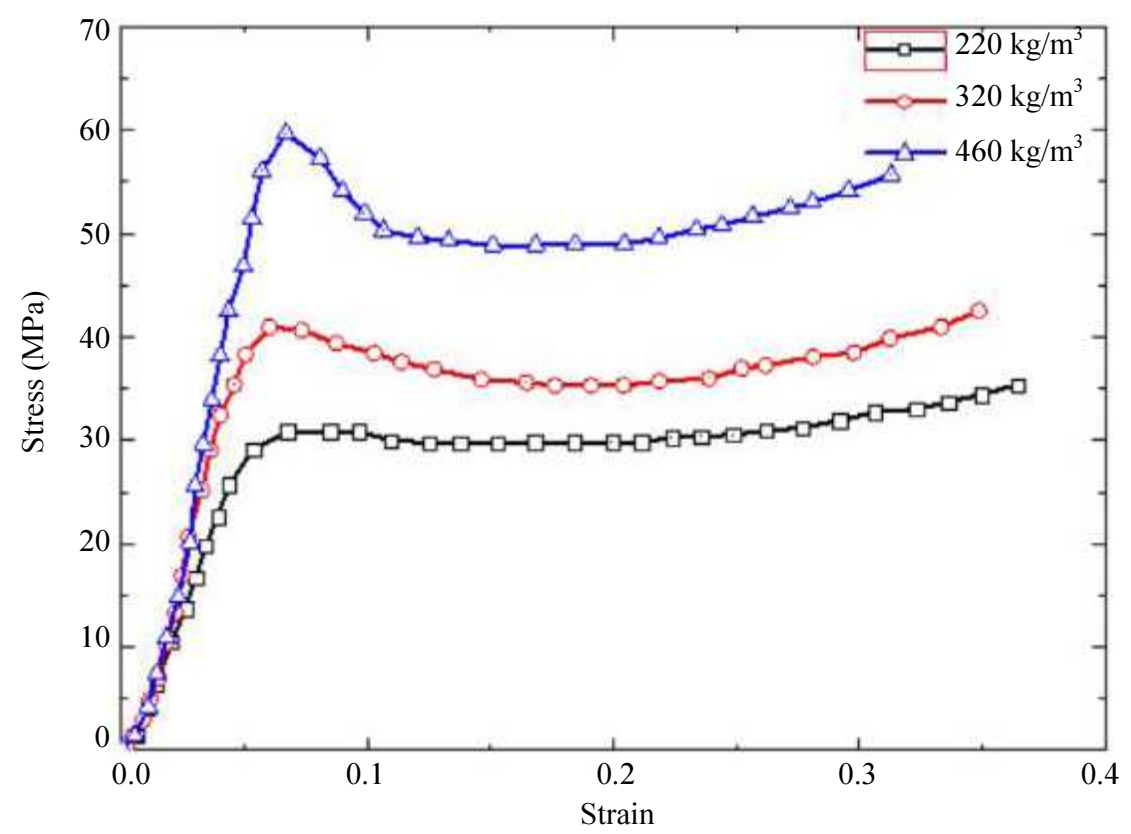

Fig. 6: Quasi-static stress-strain curve for polymeric syntactic foam (Gupta et al., 2013)
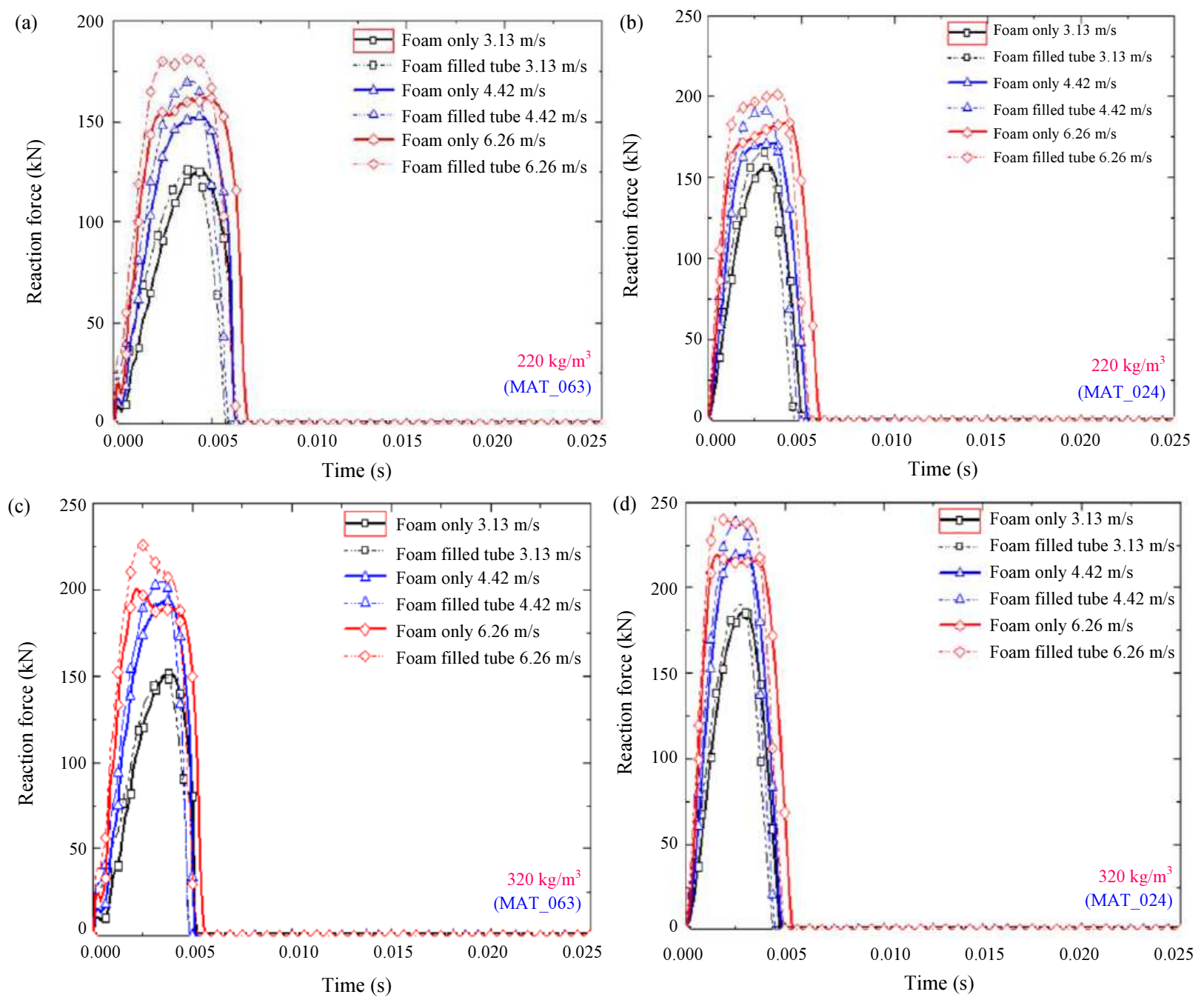
Yash M. Chordiya and Manmohan Dass Goel / International Journal of Structural Glass and Advanced Materials Research 2019, Volume 3: 40.55 DOI: $10.3844 /$ sgamrsp.2019.40.55
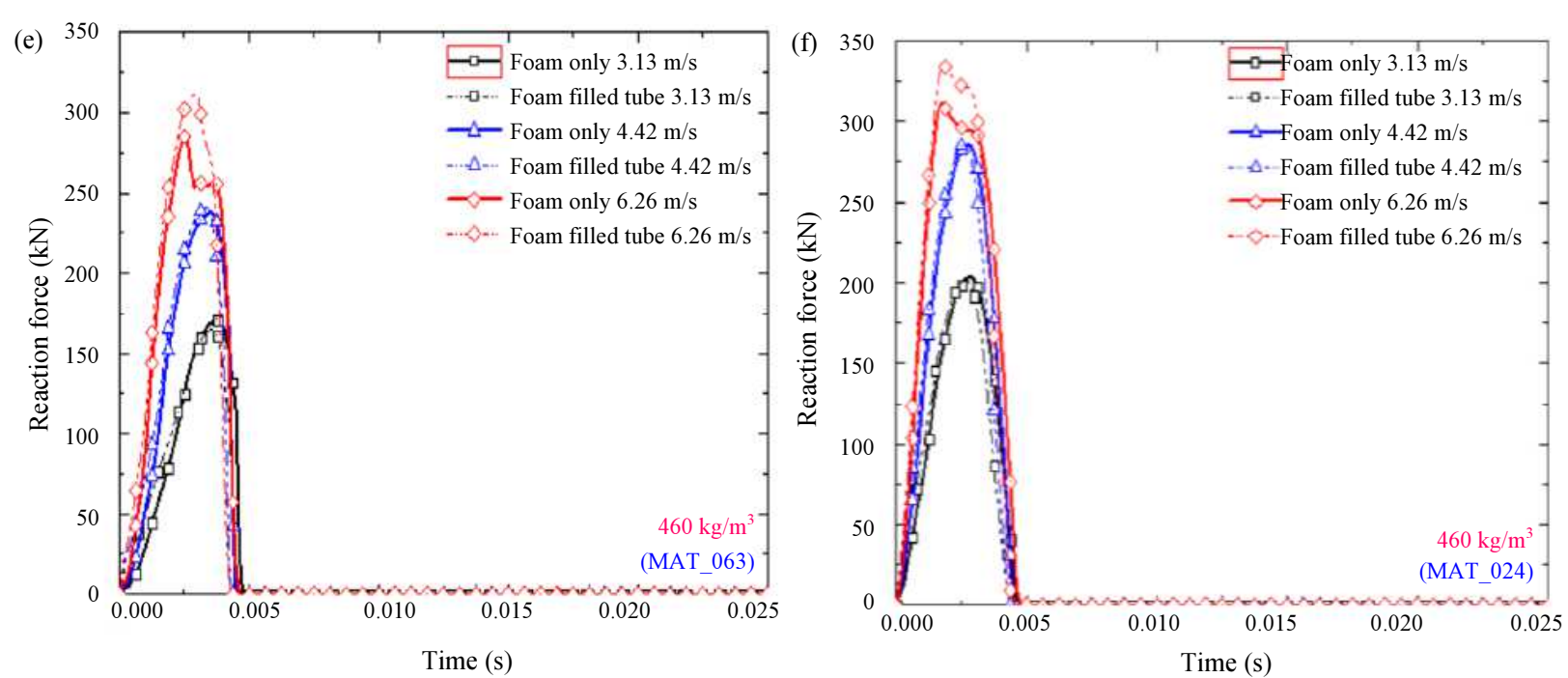

Fig. 7: Reaction force time history of polymeric syntactic foam for different densities under different impact velocity for models with foam only and foam filled tube for crushable foam and piecewise linear plasticity material model
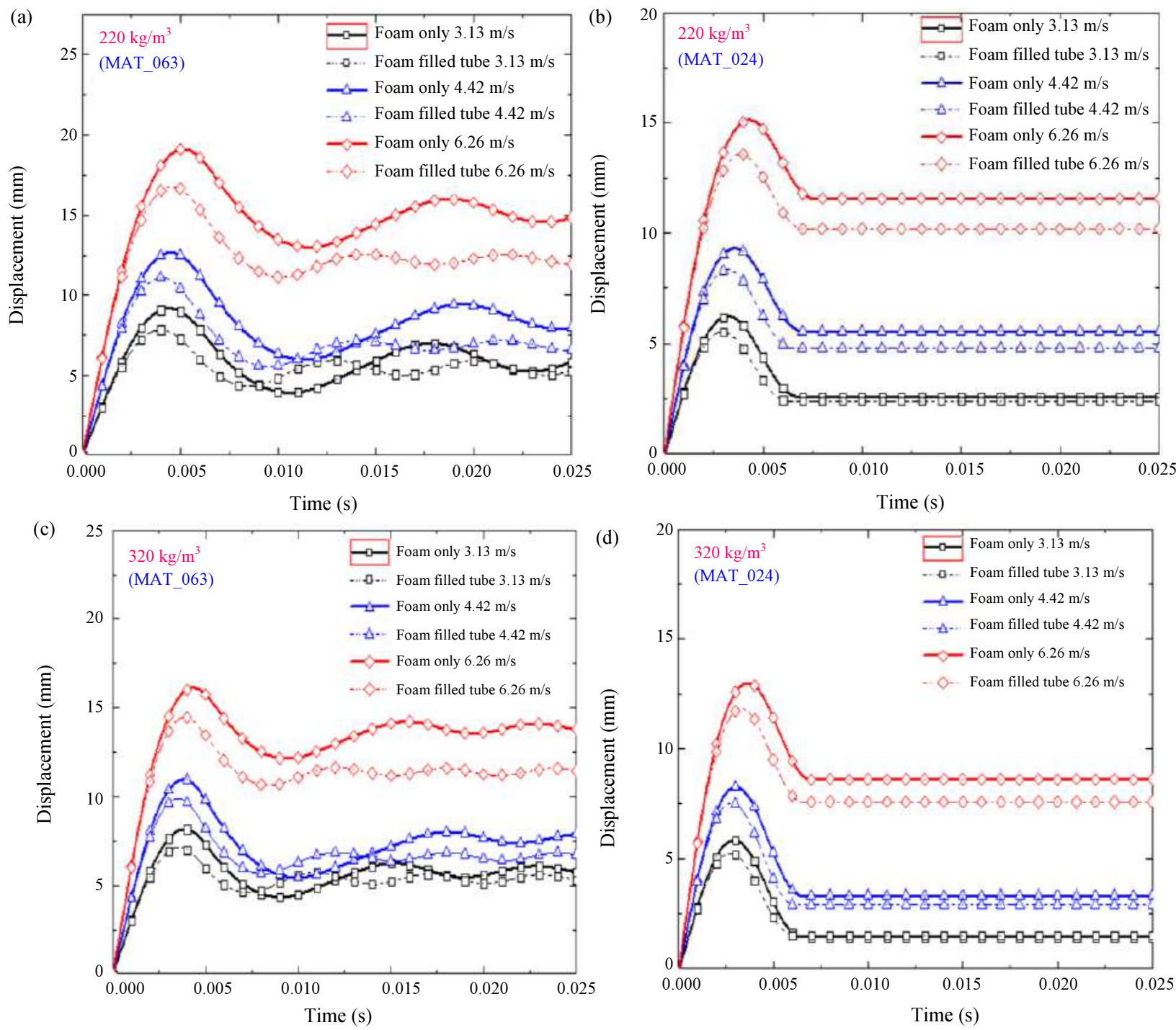

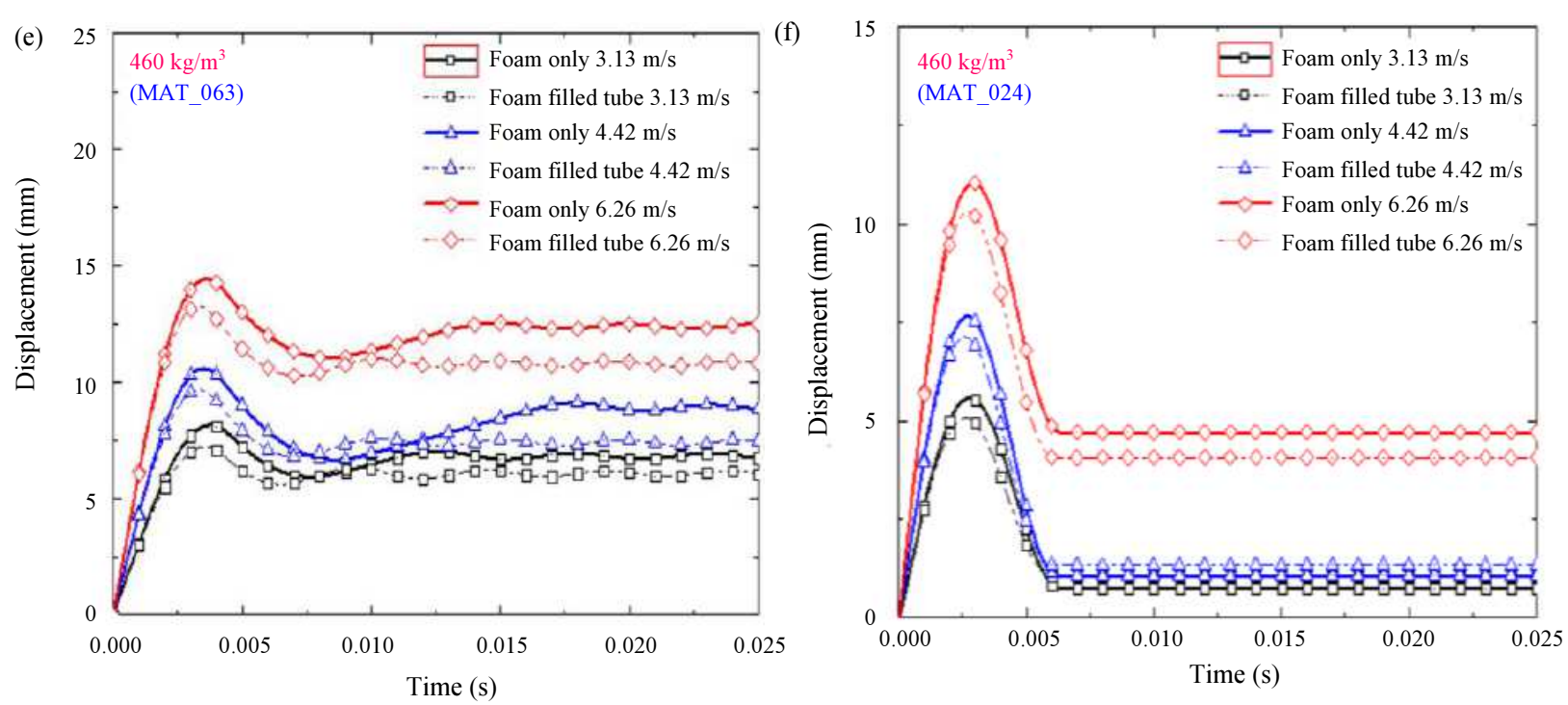

Fig. 8: Displacement time history of polymeric syntactic foam for different densities under different impact velocity for models with foam only and foam filled tube for crushable foam and piecewise linear plasticity material model

It is evident from percentage variation that foam filled tube model gives higher value of reaction force and lower value of displacement in comparison to foam only model and the reason can be attributed to the fact that deformation pattern of foams and tubes is different. Foam when compressed under loading their cell walls bend and buckle at constant stress. Whereas, tube deforms in altogether different way, it buckles into a series of regular rings until the entire tube buckles. It can be observed from the studies of previous researchers that foam filled tube gives higher collapse load in comparison to foam only configuration and a similar behaviour is observed in this study (Ashby et al., 2009; Pandarkar et al., 2016; Jones, 2011; Goel et al., 2017; 2015; 2016).

The common modes of failure of tube are ring, diamond, mixed mode. In this case Euler's buckling mode is observed wherein the foam as well as tube bulge out and only top and bottom layer bends which introduces a fold. This reason can be attributed for reducing displacement and increased resistance to deformation. As discussed previously, tube and foam deforms altogether in different manner. Tube has tendency to buckle inward but due to presence of foam as a constraint this is not possible and so the tube as well as foam bulge out. The tube which is present add on to increase the resistance to deformation and it is observed from displacement time history and reaction force time history that foam filled tube configuration gives higher reaction force and lower displacement in comparison with foam only configuration. The crushing force in tube can be calculated by Equation 5 , where in, $P_{f}$ is crushing force, $\sigma_{y}$ is yield stress, $\rho / \rho_{s}$ is ratio of relative density and $\varepsilon_{1}$ is axial strain in tube which is given by Equation 6 ( $\mathrm{Lu}$ and $\mathrm{Yu}, 2003$ ):

$$
P_{t}=0.3 \sigma_{y}\left(\frac{\rho}{\rho_{s}}\right)^{1.5} \frac{\pi D^{2}}{4}
$$

$$
\varepsilon_{1}=1-3\left(\frac{\rho}{\rho_{s}}\right)
$$

From Equation 5 it is observed that force is directly proportional to density of foam and if Equation 6 is substituted in Equation 5 then it is observed that force is directly proportional to strain and so it can be concluded that increase in density and strain rate (i.e.,) velocity leads to increase in reaction force and a similar behaviour is observed in this study. So, it can be said that foam filled tube results in enhanced energy absorption compared to foam only configuration.

Figure 9 depicts stress contours for the foam and the skin, for MAT 024 (MAT PIECEWISE LINEAR PLASTICITY) material model of density $460 \mathrm{~kg} / \mathrm{m}^{\overline{3}}$ which is impacted with hammer under impact velocity of $6.26 \mathrm{~m} / \mathrm{s}$ at time duration of $0.01 \mathrm{~s}$. The peak stress values of foam for all the models are reported in Table 3. It is observed from the stress values that foam filled tube models have lesser values of stress in comparison to foam only models. Thus, the tube along with foam results in reduced stress as compared to foam only configuration. So, in absence of tube foam will be subjected to a higher stress and hence, it leads to more deformation in the foam. Comparing all the results for peak stress values of foam filled tube configurations and foam only configurations. It is observed that presence of tube reduce the stress in the foam by 5 to $15 \%$.

Figure 10 shows force-displacement curve and it is used to calculate the energy absorbed by the material. The area under force displacement curve gives us the energy absorbed and it can be calculated by Equation 7:

$E=\int_{0}^{t} F d u$ 
A common trend is followed in all the figures that the curve increases upto a certain point and then it retraces back. The energy absorbed for all the models which is calculated with the help of Equation 7 is reported in Table 4.

By Comparing energy absorption of models comprising MAT_063 (MAT_CRUSHABLE_FOAM) material model with foam filled tube and foam only configurations, for all densities of foam considered in the present investigation under a common velocity of 6.26 $\mathrm{m} / \mathrm{s}$, it is observed that foam filled tube model results in $9.89 \%, 9.92 \%, 9.66 \%$ higher energy absorption in comparison with foam only model for density $220 \mathrm{~kg} / \mathrm{m}^{3}$, $320 \mathrm{~kg} / \mathrm{m}^{3}, 460 \mathrm{~kg} / \mathrm{m}^{3}$, respectively. Similar behaviour but different values are observed for other velocities considered in the present investigation.

Whereas, for MAT_024 (MAT_ PIECEWISE LINEAR_ PLASTICITY) comparison of energy absorption of models comprising foam filled tube and foam only configurations, for all densities of foam considered in the present investigation under a common velocity of $6.26 \mathrm{~m} / \mathrm{s}$, it is observed that foam filled tube model results in $3.86 \%, 9.38 \%, 11.67 \%$ higher energy absorption in comparison with foam only model for density $220 \mathrm{~kg} / \mathrm{m}^{3}, 320 \mathrm{~kg} / \mathrm{m}^{3}, 460 \mathrm{~kg} / \mathrm{m}^{3}$, respectively. Similar behaviour but different values are observed for other velocities considered in the present investigation.

From this study it can be concluded that increase in drop height leads to increase in all the parameters considered in the present study. In this investigation, MAT 024 (MAT_PIECEWISE_LINEAR_PLASTICITY) material model in comparison with MAT_063 (MAT_CRUSHABLE_FOAM) material model gave higher value for reaction force and energy absorption of the models and lower values for displacement. The reason for this behaviour is due to the difference in material model. MAT_063 (MAT_CRUSHABLE_FOAM) material model is modelled with damping and tension cutoff. Wherein, MAT_024 (MAT_PIECEWISE_LINEAR_PLASTICITY) approximates the complete nonlinear stress-strain curve into many linear segments, it is modelled using tangent modulus and elastic modulus.

Table 3: Peak stress values attained by polymeric syntactic foam for different material models under different drop velocities

\begin{tabular}{|c|c|c|c|c|c|}
\hline \multicolumn{3}{|l|}{ Properties } & \multicolumn{3}{|c|}{ Peak Stress Values (MPa) } \\
\hline Material model & Density $\left(\mathrm{kg} / \mathrm{m}^{3}\right)$ & Provision of tube & Velocity $=3.13 \mathrm{~m} / \mathrm{s}$ & Velocity $=4.42 \mathrm{~m} / \mathrm{s}$ & Velocity $=6.26 \mathrm{~m} / \mathrm{s}$ \\
\hline \multirow{6}{*}{$\begin{array}{l}\text { Crushable Foam } \\
\text { (MAT_063) }\end{array}$} & \multirow[t]{2}{*}{220} & Yes & 20.0 & 27.7 & 30.0 \\
\hline & & No & 23.2 & 30.0 & 33.0 \\
\hline & \multirow[t]{2}{*}{320} & Yes & 25.0 & 35.1 & 39.4 \\
\hline & & No & 28.4 & 38.0 & 42.0 \\
\hline & \multirow[t]{2}{*}{460} & Yes & 27.5 & 41.4 & 50.0 \\
\hline & & No & 32.4 & 44.5 & 54.3 \\
\hline \multirow{6}{*}{$\begin{array}{l}\text { Piecewise linear } \\
\text { Plasticity } \\
\text { (MAT_024) }\end{array}$} & \multirow[t]{2}{*}{220} & Yes & 26.8 & 30.0 & 34.0 \\
\hline & & No & 29.0 & 32.0 & 35.2 \\
\hline & \multirow[t]{2}{*}{320} & Yes & 31.8 & 37.6 & 42.0 \\
\hline & & No & 34.1 & 40.8 & 45.1 \\
\hline & \multirow[t]{2}{*}{460} & Yes & 33.5 & 48.0 & 58.6 \\
\hline & & No & 37.0 & 51.3 & 61.8 \\
\hline
\end{tabular}

Table 4: Energy absorbed by polymeric syntactic foam for different material models under different drop velocities

\begin{tabular}{llllll}
\hline \multirow{2}{*}{$\begin{array}{l}\text { Properties } \\
\text { Material Model }\end{array}$} & Density $\left(\mathrm{kg} / \mathrm{m}^{3}\right)$ & Provision of tube & Velocity $=3.13 \mathrm{~m} / \mathrm{s}$ & Velocity $=4.42 \mathrm{~m} / \mathrm{s}$ & Velocity $=6.26 \mathrm{~m} / \mathrm{s}$ \\
\hline $\begin{array}{l}\text { Crushable Foam } \\
\text { (MAT_063) }\end{array}$ & 220 & Yes & 391.24 & 852.30 & 2010.5 \\
& \multirow{2}{*}{320} & No & 359.41 & 804.72 & 1829.6 \\
& & Yes & 401.22 & 881.40 & 2050.0 \\
& \multirow{2}{*}{460} & No & 380.80 & 825.20 & 1865.0 \\
& & Yes & 431.39 & 900.00 & 2085.4 \\
Piecewise & \multirow{2}{*}{220} & No & 419.00 & 840.00 & 1902.0 \\
linear plasticity & & Yes & 472.60 & 1020.40 & 2050.0 \\
(MAT_024) & \multirow{2}{*}{320} & No & 458.67 & 961.22 & 1973.8 \\
& \multirow{2}{*}{460} & Yes & 495.00 & 1060.00 & 2210.0 \\
& & No & 478.40 & 1007.20 & 2020.4 \\
& Yes & 525.00 & 1150.00 & 2345.0 \\
\hline
\end{tabular}




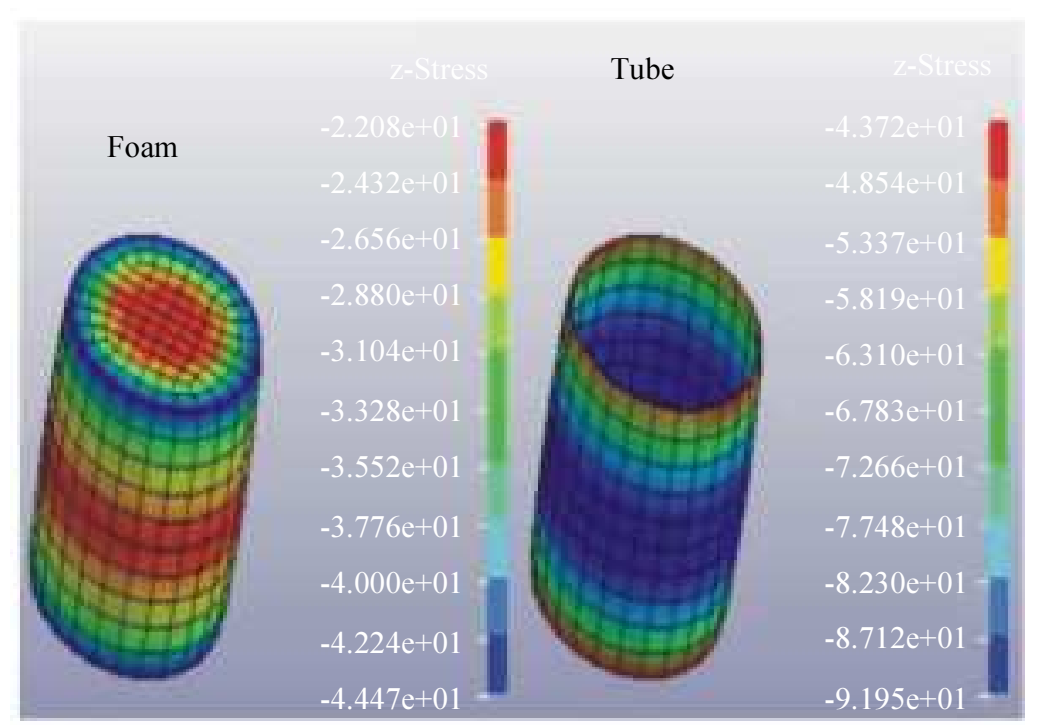

Fig. 9: Stress contours for the foam and the tube for MAT_024 (MAT_PIECEWISE_LINEAR_PLASTICITY) material model
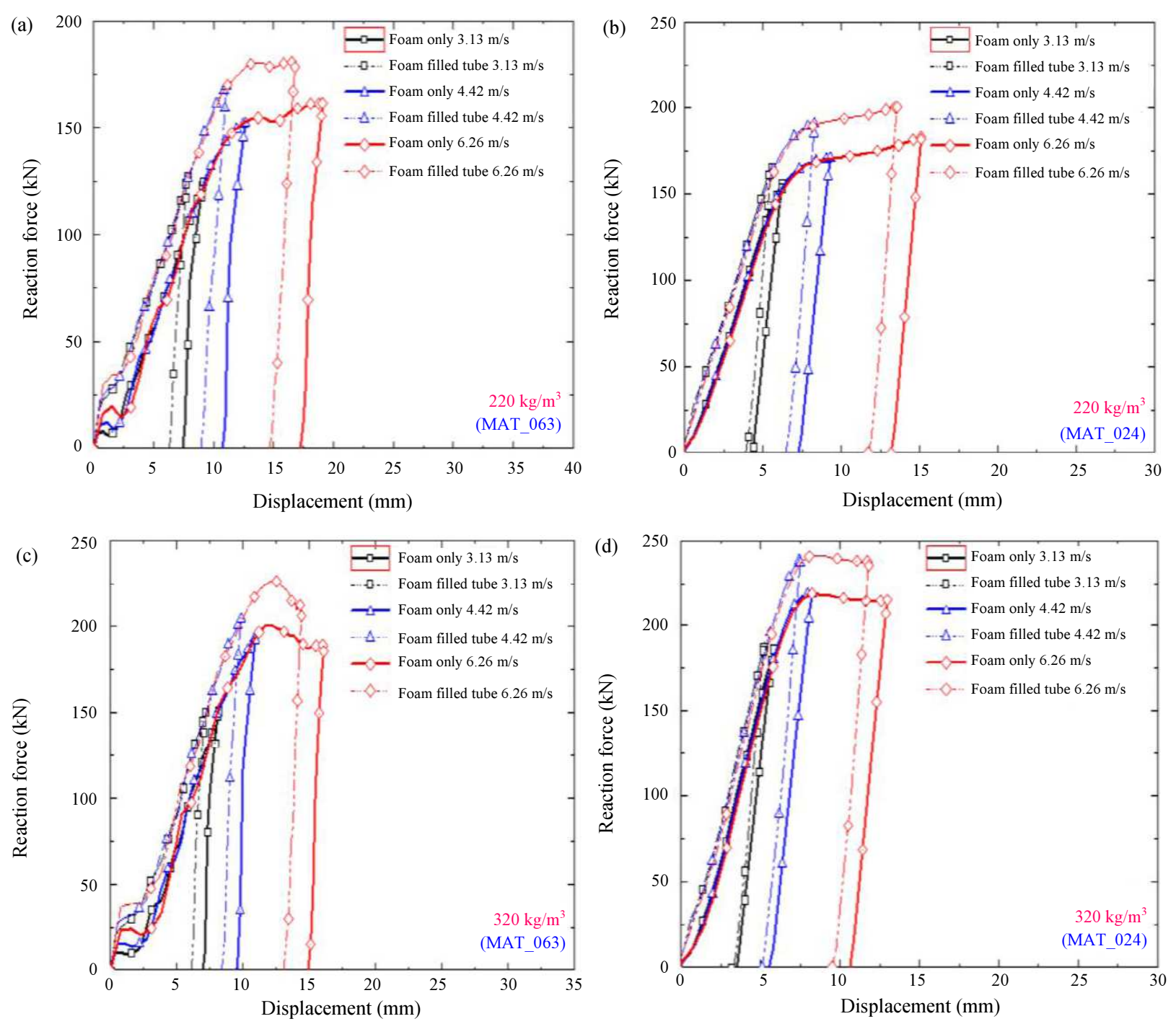

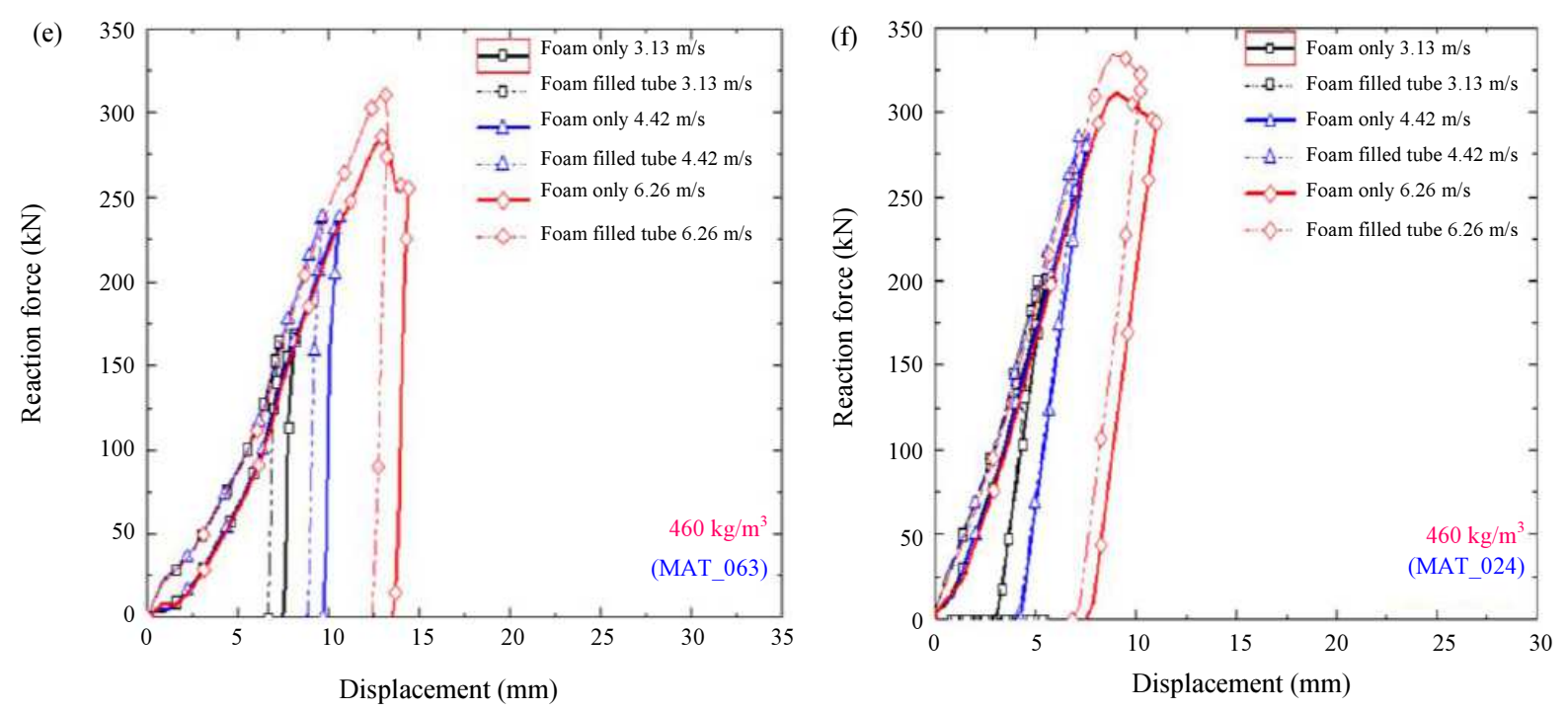

Fig. 10: Variation of force with displacement of polymeric syntactic foam for different densities under different impact velocity for models with foam only and foam filled tube for crushable foam and piecewise linear plasticity material model

To get a better understanding of the behaviour of material the parameters i.e., displacement, reaction force and energy absorbed is studied with change in velocity imparted to hammer, analysis time and density of foam. Figure 11 shows variation of displacement with density of foam and analysis time for foam filled tube and foam only models for both the material models. It can be observed from the figure that increase in density leads to reduction in displacement response.

Figure 12 shows variation of displacement with velocity of hammer and density of foam. It can be observed from figure that for MAT 063 (MAT CRUSHABLE FOAM) material model with foam filled tube configuration for density of $200 \mathrm{~kg} / \mathrm{m}^{3}$ increase in velocity from 3 to $6 \mathrm{~m} / \mathrm{s}$ leads to increase in displacement from $7.816 \mathrm{~mm}$ to $16.78 \mathrm{~mm}$. Whereas, corresponding values for $500 \mathrm{~kg} / \mathrm{m}^{3}$ is 7.21 to $13.26 \mathrm{~mm}$. Similar behaviour but different values are observed in the other models.

Figure 13 shows variation of energy absorption with velocity of hammer and density of foam. It can be observed from figure that for MAT 063 (MAT CRUSHABLE FOAM) material model with foam only configuration for density of $200 \mathrm{~kg} / \mathrm{m}^{3}$ increase in velocity from 3 to $6 \mathrm{~m} / \mathrm{s}$ leads to increase in energy absorption from 359.41 to $1829.58 \mathrm{~J}$ whereas corresponding values for $500 \mathrm{~kg} / \mathrm{m}^{3}$ is 418.29 to $1902 \mathrm{~J}$. Similar behaviour but different values are observed in the other models.

Figure 14 shows variation of reaction force with velocity of hammer and density of foam. It can be observed from figure that for MAT_024 (PIECEWISE_LINEAR_PLASTICITY) material model with foam filled tube configuration for density of 200 $\mathrm{kg} / \mathrm{m}^{3}$ increase in velocity from 3 to $6 \mathrm{~m} / \mathrm{s}$ leads to increase in reaction force from 165.97 to $201.45 \mathrm{kN}$ whereas corresponding values for $500 \mathrm{~kg} / \mathrm{m}^{3}$ is 201.96 to $333.67 \mathrm{kN}$. Similar behaviour but different values are observed in the other models.

Figure 15 shows variation of displacement with velocity of hammer and analysis time for models with foam filled tube and foam only configuration for both the material models. It can be observed from the figure that increases in velocity leads to increase in displacement response. The maximum displacement of foam is observed for MAT 063 (MAT_CRUSHABLE_FOAM) material model with foam only configuration.

\section{Conclusion}

Based on this investigation, following conclusions are drawn in accordance with the objective defined:

1. The time required for the peak reaction and peak displacement is same for both the material models i.e., MAT_063 and MAT_024 for all the velocities considered in the present study

2. Increase in density leads to increase in reaction force, decrease in displacement and increase in energy absorption for all the velocities considered in the present investigation

3. For a particular density and material model, increase in velocity leads to increase in all the parameters considered in the present investigation

4. Effect of tube is dominant for low density foam i.e., $220 \mathrm{~kg} / \mathrm{m}^{3}$ for all the velocities, whereas for 460 $\mathrm{kg} / \mathrm{m}^{3}$ the effect is observed only for $6.26 \mathrm{~m} / \mathrm{s}$ 

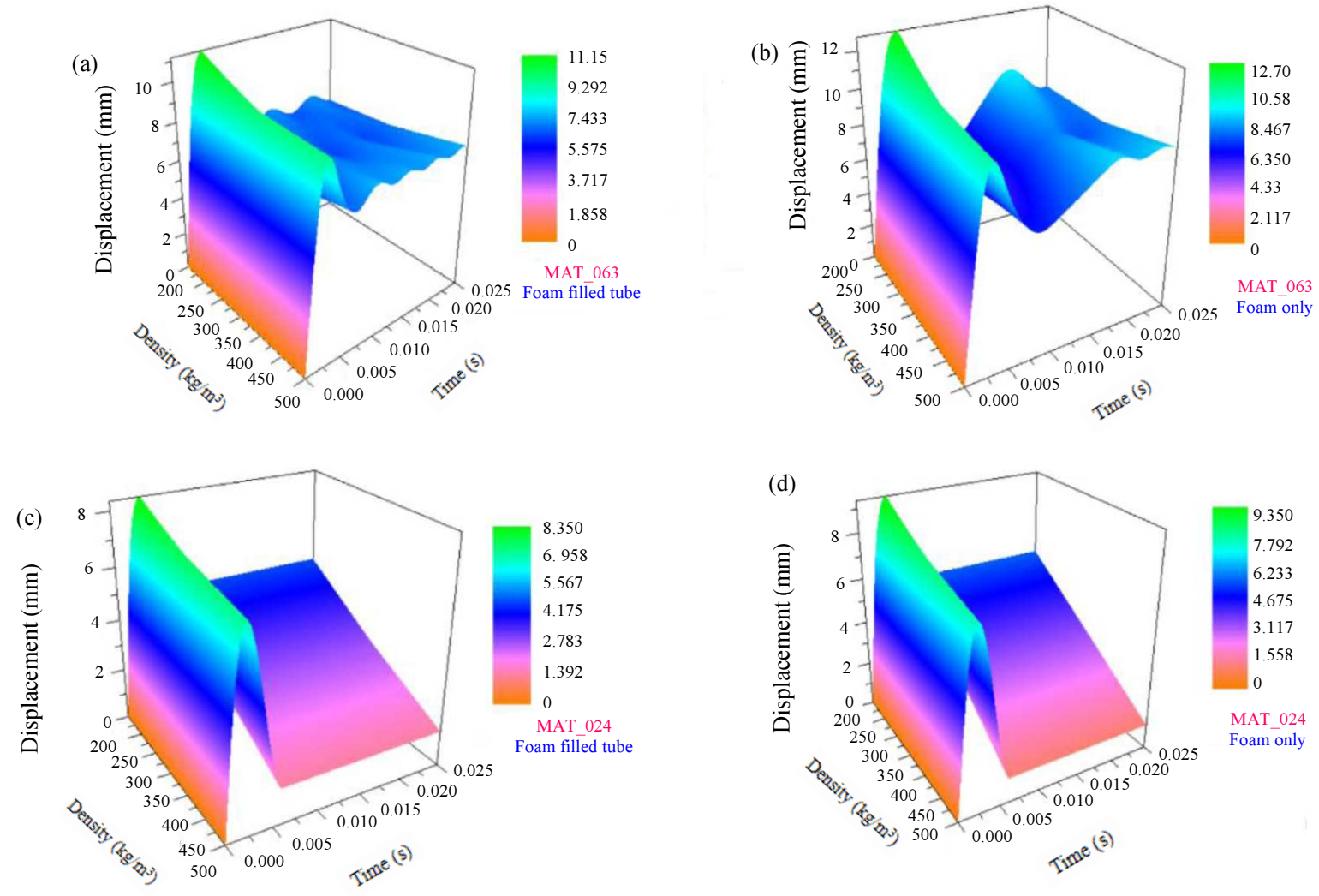

Fig. 11: Variation of displacement with density and time for crushable foam and piecewise linear plasticity material model
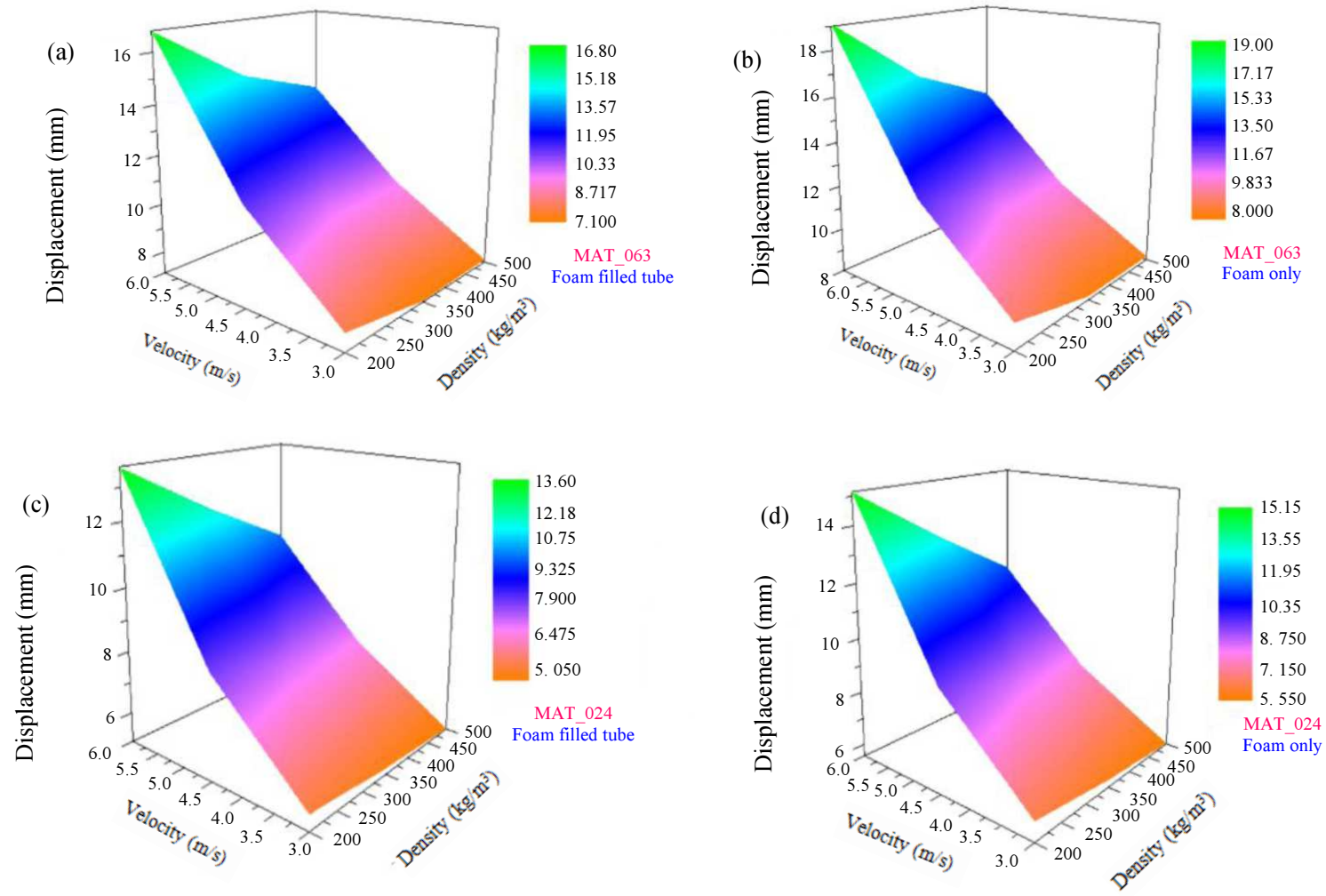

Fig. 12: Variation of displacement with velocity and density for crushable foam and piecewise linear plasticity material model 

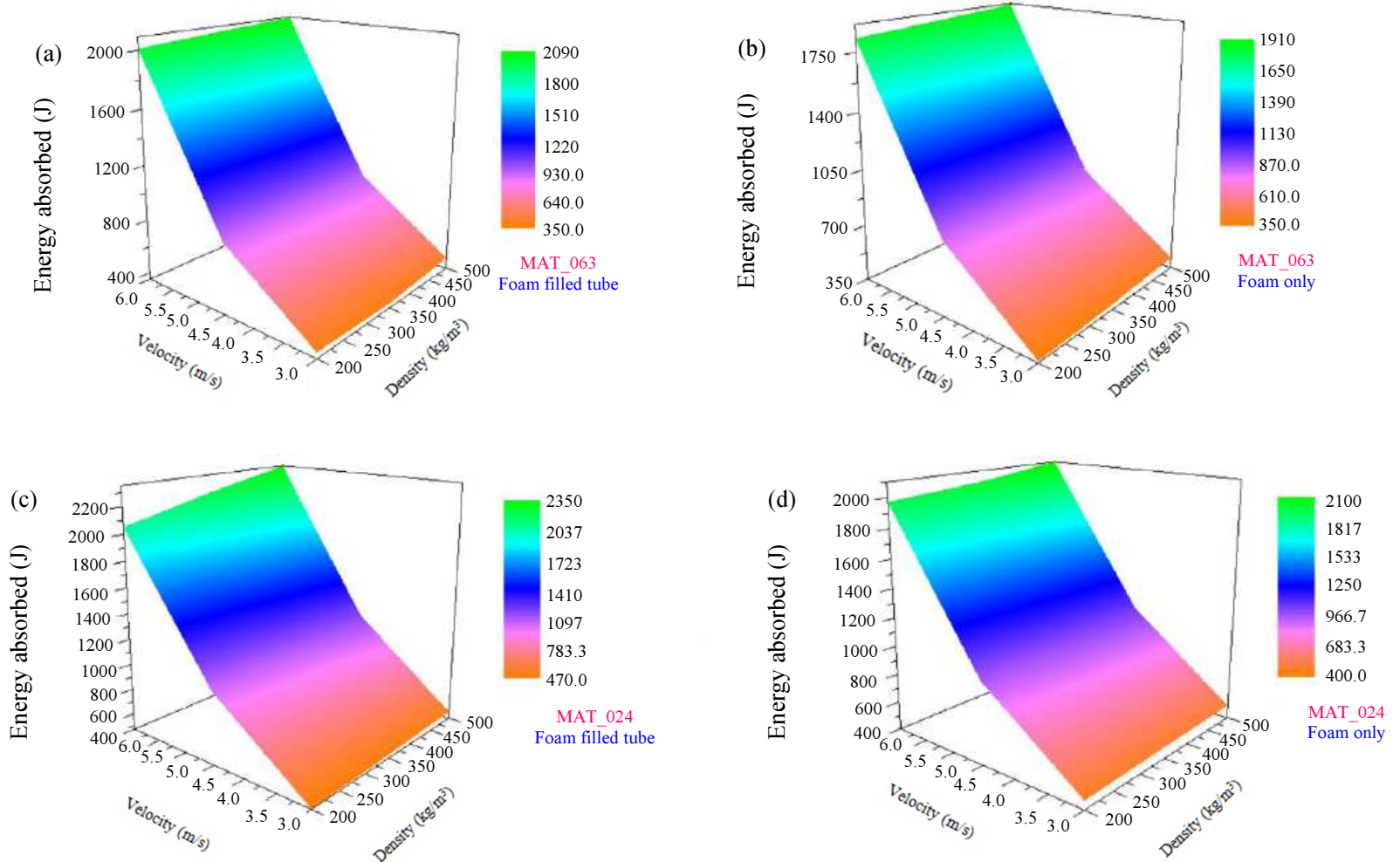

Fig. 13: Variation of energy absorbed with velocity and density for crushable foam and piecewise linear plasticity material model
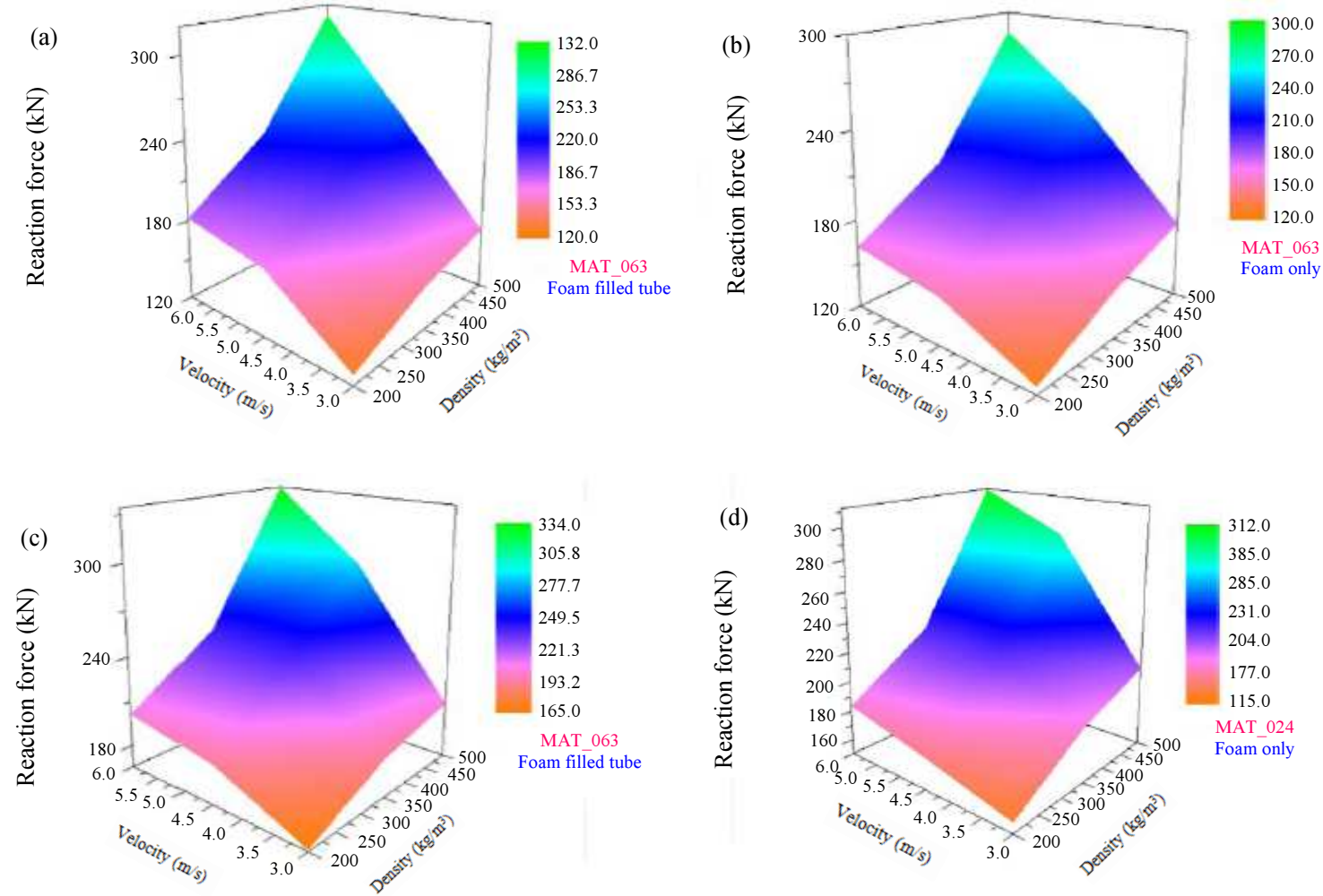

Fig. 14: Variation of reaction force with velocity and density for crushable foam and piecewise linear plasticity material model 

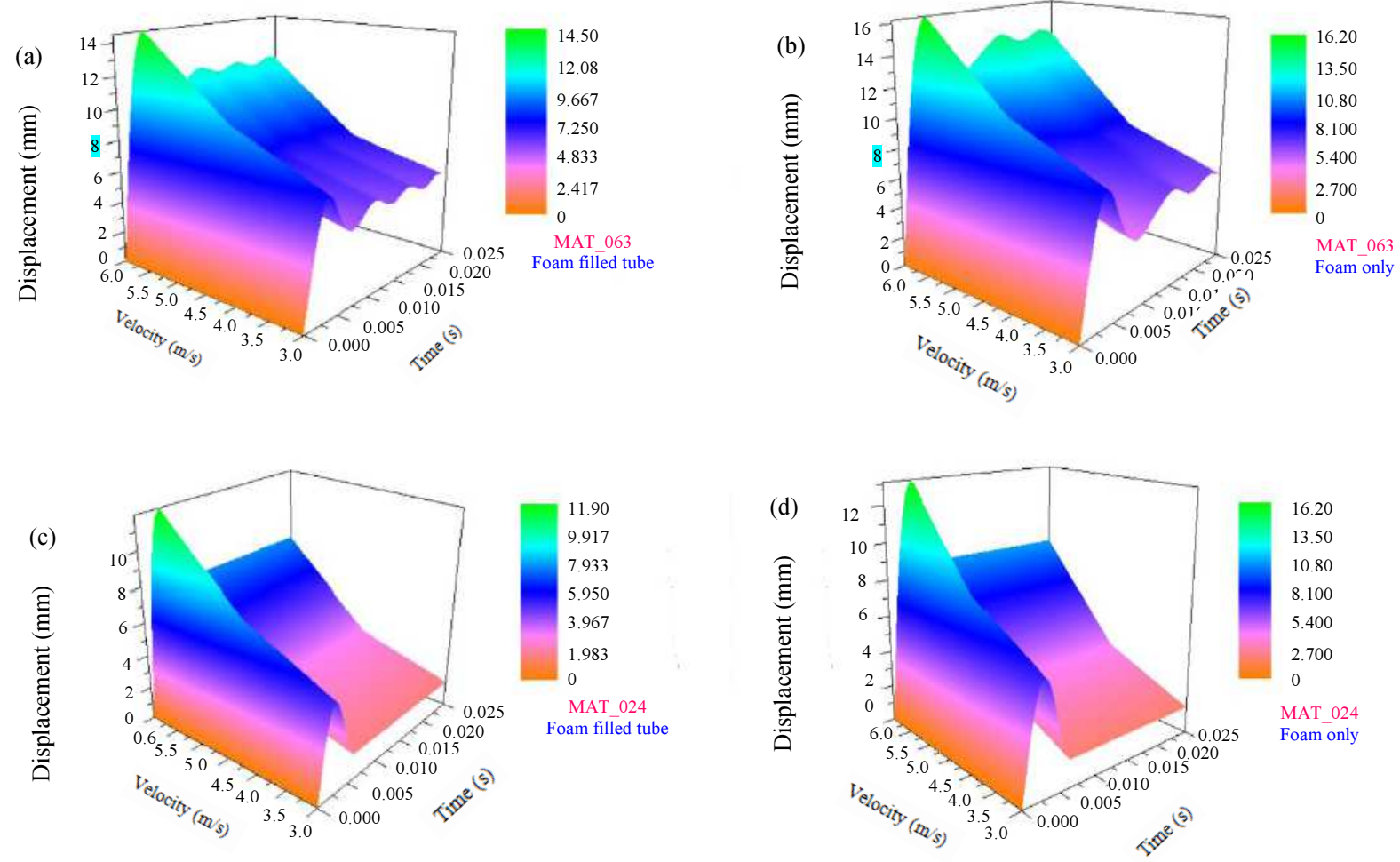

Fig. 15: Variation of displacement with velocity and time for crushable foam and piecewise linear plasticity material model

\section{Author's Contributions}

Yash M. Chordiya: Worked on the development of numerical model and parametric study. This is part of $\mathrm{M}$. Tech. dissertation under the guidance and supervision of Dr. Manmohan Dass Goel. Mr. Yash prepared the first draft of the manuscript in discussion with Dr. Goel.

Manmohan Dass Goel: Conceptualization the idea and guided the student (Mr. Yash) for completing this work. Further, manuscript is reviewed and modified by Dr. Goel.

\section{Ethics}

This article is original and contains unpublished material. The corresponding author confirms that all of the other authors have read and approved the manuscript and no ethical issues involved.

\section{References}

Aldoshan, A., D.P. Mondal and S. Khanna, 2017. Dynamic high temperature compression of carbon nanotubes reinforced aluminum foams. J. Dynamic Behav. Mater., 3: 1-11. DOI: 10.1007/s40870-016-0088-9

Ashby, M., A. Evans, N. Fleck, L. Gibson and J. Hutchinson et al., 2009. Metal Foams: A Design Guide. 1st Edn., Elsevier, Boston.

ISBN-10: 0080511465, pp: 251.
Aymerich, F., P. Marcialis, S. Meili and P. Priolo, 1997. An instrumented drop weight machine for low velocity impact testing. Transact. Built Environ., 34: 53-58.

Banthia, N., S. Mindess, A. Bentur and M. Pigeon, 1989. Impact testing of concrete using a dropweight impact machine. Experimental Mechanics, 29: 63-69. DOI: 10.1007/BF02327783

Barr, B. and A. Bouamrata, 1988. Development of a repeated dropweight impact testing apparatus for studying fibre reinforced concrete materials. Composites, 19: 453-466. DOI: 10.1016/0010-4361(88)90703-3

Bhattacharya, S., K.C. Krishnamurthy, R. Rajendran, K. Prem Sai and S. Basu, 2006. Impact studies on structural components using a free-flight drop tower. Exp. Tech., 30: 52-58.

DOI: $10.1111 / \mathrm{j} .1747-1567.2006 .00018 . \mathrm{x}$

Bowles, K., 1988. The correlation of low-velocity impact resistance of graphite-fiber-reinforced composites with matrix properties. Proceedings of the ASTM International Composite Materials: Testing and Design (Eighth Conference), Barr Harbor Drive, West Conshohocken, pp: 124-124. DOI: $10.1520 / \mathrm{STP} 26131 \mathrm{~S}$ 
Chordiya, Y.M. and M.D. Goel, 2018. Study of impact behavior of polymeric foams using numerical simulation of drop weight impact. Proceedings of National Conference: Advanced Structures, Materials and Methodology in Civil Engineering, Nov. 3-4, NIT Jalandhar, India, pp: 227-233.

Goel, M.D., 2016. Numerical investigation of the axial impact loading behaviour of single, double and stiffened circular tubes. Int. J. Crashworthiness. 21: 41-50. DOI: 10.1080/13588265.2015.1113617

Goel, M.D., 2015. Deformation, energy absorption and crushing behavior of single, double and multi-wall foam filled square and circular tubes. Thin-Walled Structures, 90: 1-11. DOI: 10.1016/j.tws.2015.01.004

Goel, M.D., A. Pandharkar and M.S. Hora, 2017. Numerical simulation of crushing and energy absorption behavior of twisted tubes under impact loading. Procedia Eng., 173: 1365-1373.

DOI: 10.1016/j.proeng.2016.12.182

Goel, M.D., D.P. Mondal, M.S. Yadav and S.K. Gupta, 2014. Effect of strain rate and relative density on compressive deformation behavior of aluminum cenosphere syntactic foam. Materials Sci. Eng., 590: 406-415. DOI: 10.1016/j.msea.2013.10.048

Goel, M.D., V.A. Matsagar and A.K. Gupta, 2015. Blast resistance of stiffened sandwich panels with aluminum cenosphere syntactic foam. Int. J. Impact Eng., 77: 134-146. DOI: 10.1016/j.ijimpeng.2014.11.017

Goel, M.D., V.A. Matsagar, S. Marburg and A.K. Gupta, 2013. Comparative performance of stiffened sandwich foam panels under impulsive loading. J. Perform. Constructed Facilities. 27: 540-549. DOI: 10.1061/(ASCE)CF.1943-5509.0000340

Goyal, S. and E.K. Buratynski, 2000. Methods for realistic drop-testing. Int. J. Microcircuits Elect. Packag., 23: 45-52.

Gunawan, L., T. Dirgantara and I.S. Putra, 2011. Development of a dropped weight impact testing machine. Int. J. Eng. Technol., 11: 120-126.

Gupta, N., D. Pinisetty and V.C. Shunmugasamy, 2013. Reinforced Polymer Matrix Syntactic Foams, SpringerBriefs in Materials. 1st Edn., Springer International Publishing, Cham.

IPR, 2019. Report on Indian population retrieved from $\mathrm{http}: / /$ worldpopulationreview.com/countries/india.

Johnson, N.L. and A.L. Browne, 2002. Dynamic crush tests using a "free-flight" drop tower: Theory. Experimental Techniques. 26: 43-46.

Johnson, W., 1972. Impact Strength of Materials. 1st Edn., Edward Arnold, London, ISBN-10: 0-71313266-3, 361 .

Jones, N., 2011. Structural Impact. 2nd Edn., Cambridge University Press, ISBN-10: 1139206478, pp: 584.
LS-DYNA, 2019. Livermore Software Technology Corporation, 1st Edn., Livermore, California, U.S.A,

Lu, G. and T. Yu, 2003. Energy Absorption of Structures and Materials. 1st Edn., CRC Press, Boca Raton. ISBN-10: 1855738589, pp: 424.

Matsagar, V.A., 2014. Computing stress and displacement response of composite plates under blast. Disaster Advances. 7: 23-38.

MRTHTRW, 2016. Road accidents in India. Government of India, New Delhi.

Pandarkar, A., M.D. Goel and M.S. Hora, 2016. Axial crushing of hollow and foam filled tubes: An overview. Sādhanā, 41: 909-921. DOI: $10.1007 / \mathrm{s} 12046-016-0525-4$

Pinnoji, P.K., P. Mahajan, N. Bourdet, C. Deck and R. Willinger, 2009. Impact dynamics of metal foam shells for motorcycle helmets: Experiments and numerical modeling. Int. J. Impact Eng., 37: 274-284. DOI: 10.1016/j.ijimpeng.2009.05.013

Rajendran, R., A. Moorthi and S. Basu, 2009. Numerical simulation of drop weight impact behaviour of closed cell aluminium foam. Materials Design, 30: 2823-2830. DOI: 10.1016/j.matdes.2009.01.026

Roesset, J.M., E. Kausel, V. Cuellar, J.L. Monte and J. Valerio, 1994. Impact of weight falling onto the ground. J. Geotechnical Eng., 120: 1394-1412. DOI: 10.1061/(ASCE)0733-9410(1994)120:8(1394)

Sahu, S., D.P. Mondal, J.U. Cho, M.D. Goel and M.Z. Ansari, 2019. Low-velocity impact characteristics of closed cell AA2014-SiCp composite foam. Composites Part B Eng., 160: 394-401. DOI: 10.1016/j.compositesb.2018.12.054

SaveLIFE Foundation, 2017. Road safety in India., SaveLIFE Foundation.

Behrooz, T.F., M.M. Shokrieh and H.R. Abdolvand, 2013. Designing and manufacturing of a drop weight impact test machine. Eng. Solid Mechanics. 1: 69-76. DOI: 10.5267/j.esm.2013.08.001

VPCR, 2015. Report on list of countries by vehicle per capita retrieved from. https://en.wikipedia.org/wiki/List_of_countries _by_vehicles_per_capita

Zhang, J., M. Maalej and S.T. Quek, 2007. Performance of hybrid-fiber ECC blast/shelter panels subjected to drop weight impact. J. Materials Civil Eng., 19: 855-863. DOI: 10.1061/(ASCE)0899-1561(2007)19:10(855)

Zhang, W., S. Chen and Y. Liu, 2017. Effect of weight and drop height of hammer on the flexural impact performance of fiber-reinforced concrete. Construct. Build. Mater., 140: 31-35.

DOI: $10.1016 /$ j.conbuildmat.2017.02.098 